ARTICLE

https://doi.org/10.1038/s41467-019-14223-w

\title{
Recover the activity of sintered supported catalysts by nitrogen-doped carbon atomization
}

Huang Zhou,7, Yafei Zhao ${ }^{1,7}$, Jie Xu ${ }^{2,7}$, Haoran Sun ${ }^{3}$, Zhijun Li ${ }^{1}$, Wei Liü ${ }^{3 \star}$, Tongwei Yuan ${ }^{4}$, Wei Liu ${ }^{5}$, Xiaoqian Wang ${ }^{1}$, Weng-Chon Cheong $\mathbb{1}^{6}{ }^{6}$, Zhiyuan Wang ${ }^{1}$, Xin Wang ${ }^{1}$, Chao Zhao ${ }^{1}$, Yancai Yao ${ }^{1}$, Wenyu Wang ${ }^{1}$,

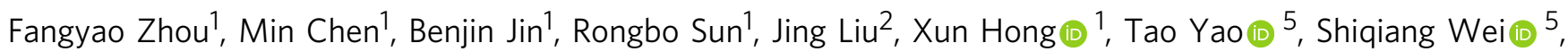
Jun Luo (i) ${ }^{2 \star} \&$ Yuen Wu (D) ${ }^{1,3 *}$

The sintering of supported metal nanoparticles is a major route to the deactivation of industrial heterogeneous catalysts, which largely increase the cost and decrease the productivity. Here, we discover that supported palladium/gold/platinum nanoparticles distributed at the interface of oxide supports and nitrogen-doped carbon shells would undergo an unexpected nitrogen-doped carbon atomization process against the sintering at high temperatures, during which the nanoparticles can be transformed into more active atomic species. The in situ transmission electron microscopy images reveal the abundant nitrogen defects in carbon shells provide atomic diffusion sites for the mobile atomistic palladium species detached from the palladium nanoparticles. More important, the catalytic activity of sintered and deactivated palladium catalyst can be recovered by this unique $\mathrm{N}$-doped carbon atomization process. Our findings open up a window to preparation of sintering-resistant single atoms catalysts and regeneration of deactivated industrial catalysts.

\footnotetext{
${ }^{1}$ Hefei National Laboratory for Physical Sciences at the Microscale, Collaborative Innovation Center of Chemistry for Energy Materials (iChEM), School of Chemistry and Materials Science, and National Synchrotron Radiation Laboratory, University of Science and Technology of China, Hefei 230026, China. ${ }^{2}$ Center for Electron Microscopy and Tianjin Key Lab of Advanced Functional Porous Materials, Institute for New Energy Materials \& Low-Carbon Technologies, School of Materials Science and Engineering, Tianjin University of Technology, Tianjin 300384, China. ${ }^{3}$ Nano and Heterogeneous Materials Center, School of Materials Science and Engineering, Nanjing University of Science and Technology, Nanjing 210094, China. ${ }^{4}$ NEST Lab, Department of Chemistry, College of Science, Shanghai University, Shanghai 200444, China. ${ }^{5}$ National Synchrotron Radiation Laboratory, University of Science and Technology of China, Hefei 230029, China. ${ }^{6}$ Department of Chemistry, Tsinghua University, Beijing 100084, China. ${ }^{7}$ These authors contributed equally: Huang Zhou, Yafei Zhao, Jie Xu. *email: weiliu@njust.edu.cn; jluo@tjut.edu.cn; yuenwu@ustc.edu.cn
} 
S upported metal catalysts can efficiently accomplish many important industrial applications in heterogeneous catalysis, including the production of chemicals ${ }^{1}$, pharmaceuticals ${ }^{2}$ and clean fuels ${ }^{3}$, and the purification of vehicle emissions ${ }^{4-7}$. However, most of the supported catalysts suffer from sintering, which significantly decrease their active surface areas, stability, and shut down the catalytic steps ${ }^{6,8-11}$. The sintering is usually accelerated above the Tammann temperature (half of the melting point in absolute units) ${ }^{4,12}$, involving the emission of mobile species from small particles and their capture by large particles (Ostwald ripening), or particles migration and coalescence ${ }^{7,8,12}$. This process is costly, particularly for those supported Earthscarce metals such as Pt (refs. ${ }^{7,13-16}$ ), Pd (refs. 17,18), Au (refs. $5,10,19,20$ ), because the deactivated metal nanoparticles (NPs) should be replaced to satisfy the industrial-level efficiency. For example, replacing catalysts in a fuel cell stack would cost $>50 \%$ expenditure due to the valuable price of Pt-based catalysts ${ }^{3}$. Therefore, there is primary interest in inspiring researchers in academia and industry to construct sintering-resistant catalysts and cut down the costs for catalyst regeneration and recovery.

Of note is that, increasing the metal-support interaction (MSI) has been widely utilized to remit the sintering propensity of supported metal catalysts ${ }^{5,17,21-27}$. One of the effective strategies to prevent particles sintering is confining metal NPs with porous supports, such as mesoporous alumina ${ }^{4,28-30}$, silica ${ }^{20,21,26,31}$, ceria $^{7}$, or titanium ${ }^{22,32}$. Another typical strategy to enhance the stabilization of metal NPs on supports is to introduce strong ligands ${ }^{33,34}$. However, the steric hindrance of porous support and organic ligands on metal catalysts would block catalytic active sites and alter the activity and selectivity. Currently, two major challenges remain in the industry of supported metal catalysts: (i) preparation of catalysts that can resist sintering at high temperatures, and (ii) strategy to recover or regenerate the activity of sintered and deactivated catalysts.

In a recent interesting work ${ }^{18}, \mathrm{Li}$ et al. describe that the metal NPs can be transformed to thermally stable single atoms with assistence of nitrogen $(\mathrm{N})$ defects at high temperatures. Inspired by this work, herein, we report a $\mathrm{N}$-doped carbon atomization process to not only redisperse oxide supported metal NPs but also regenerate the sintered and deactivated supported metal catalysts. The $\mathrm{N}$-doped carbon atomization process is opposite to the conventional sintering, during which the sintering of supported $\mathrm{Pd} / \mathrm{Au} / \mathrm{Pt} \mathrm{NPs}$ on oxide supports is largely prohibited by covering the NPs with a N-doped carbon shell. This carbon shell containing abundant $\mathrm{N}$ defects allows the migration of atomic metal species detached from the large NPs at high temperatures, but impedes the large NPs. After the N-doped carbon atomization process, the as-obtained sintering-resistant Pd SAs exhibit superior activity for hydrogenation reactions with respect to Pd NPs.

\section{Results}

The conventional sintering of Pd NPs supported on $\mathrm{TiO}_{2}$ is displayed in Fig. 1a. The Pd NPs homogeneously supported on the surface of $\mathrm{TiO}_{2}$ (denoted as $\mathrm{Pd} \mathrm{NPs} / \mathrm{TiO}_{2}$ ) aggregated to form large particles (from 3.40 to $14.53 \mathrm{~nm}$ ) at $900{ }^{\circ} \mathrm{C}$ for $3 \mathrm{~h}$ (Fig. 1b; Supplementary Figs. 1, 2). By contrast, N-doped carbon atomization showed a totally different situation, in which small Pd NPs were transformed to atomically dispersed species (Fig. 1c-g). Specifically, a polydopamine (PDA) layer was deposited on the surface to form a core-shell structure (denoted as $\mathrm{Pd} \mathrm{NPs} / \mathrm{TiO}_{2} @ \mathrm{PDA}$, Fig. 1c; Supplementary Fig. 3), as evidenced by a typical stretching vibration for $\mathrm{N} / \mathrm{O}-\mathrm{H}$ at $3450 \mathrm{~cm}^{-1}$ and a bending vibration of $\mathrm{N}-\mathrm{H}$ at $1615 \mathrm{~cm}^{-1}$ in Fourier-transformed infrared (FT-IR) spectroscopy ${ }^{5}$ (Supplementary Fig. 4). Although the color of Pd
$\mathrm{NPs} / \mathrm{TiO}_{2}$ changed from gray to dark brown (Supplementary Fig. 5), the particle size of Pd NPs retained as $\sim 3.38 \mathrm{~nm}$ (Supplementary Fig. 3). Then, the PDA layer was transformed in situ to form $\mathrm{N}$-doped carbon shells after carbonization at $900^{\circ} \mathrm{C}$ under argon (Ar) atmosphere (Fig. 1f; Supplementary Fig. 6). The depressed signal for the organic species $(\mathrm{N} / \mathrm{O}-\mathrm{H})$ in the FT-IR spectra and the appearance of characteristic D $\left(1350 \mathrm{~cm}^{-1}\right)$ and $\mathrm{G}\left(1580 \mathrm{~cm}^{-1}\right)$ bands of carbon species in Raman spectra (Supplementary Figs. 4, 7) both traced this evolution. The coated $\mathrm{N}$-doped carbon layer could serve as a "protector" to limit the migration of supported Pd NPs and their following aggregation. Meanwhile, $\mathrm{TiO}_{2}$ was reduced into defective $\mathrm{TiO}_{2}$ slowly, and the atomic-scale species emitted from supported Pd NPs diffused into the carbon layers (Fig. 1f; Supplementary Fig. 6), in which the abundant $\mathrm{N}$ defects are essential for the transformation of Pd NPs to SAs (Supplementary Figs. 8, 9). The specific chemical environments of $\mathrm{N}$ were investigated by X-ray photoelectron spectroscopy (XPS) and the near-edge X-ray absorption fine structures (NEXAFS) (Supplementary Fig. 10). The pyrolyzed Ndoped carbon shells were determined to be $5.4 \mathrm{wt} \%$ by a thermogravimetric analysis (TGA) (Supplementary Fig. 11), and can be removed subsequently by a post-thermal treatment in air at $500^{\circ} \mathrm{C}$. This is accompanied with a dramatic color change from black to light yellow (Supplementary Fig. 5), also supported by the vanishment of carbon signals in FT-IR and Raman spectra (Supplementary Figs. 4, 7). To our surprise, though there is no conspicuous Pd NPs or clusters observed by the transmission electron-microscopy (TEM) measurements (Fig. 1g), the signals detected from the energy-dispersive X-ray spectroscopy (EDS) analysis and the inductively coupled plasma optical emission spectrometry (ICP-OES) measurements highlighted the existence of Pd species on $\mathrm{TiO}_{2}$ surface (Supplementary Fig. 12, Supplementary Table 1). Considering the high boiling point of $\mathrm{Pd}$ $\left(\mathrm{mp} 1555^{\circ} \mathrm{C} \text {, bp } 2970^{\circ} \mathrm{C}\right)^{12}$, it is reasonable to propose that the resultant $\mathrm{Pd}$ species are atomic scale and the transformation from NPs to SAs indeed took place.

To investigate the intrinsic mechanism of high temperature and $\mathrm{N}$-doped carbon atomization, the evolution process from $\mathrm{Pd}$ $\mathrm{NPs} / \mathrm{TiO}_{2} @ \mathrm{PDA}$ to $\mathrm{Pd} \mathrm{SAs} / \mathrm{TiO}_{2} @ \mathrm{C}$ was further traced by in situ TEM. Representative TEM images acquired at different temperatures (Supplementary Fig. 14) showed that no observable change occurred in size distribution and particle number of the supported Pd NPs when the temperature was lower than $800^{\circ} \mathrm{C}$, indicating the migration and aggregation were largely prohibited by the carbon layer. Interestingly, as the temperature was elevated over $800^{\circ} \mathrm{C}$, the $\mathrm{N}$-doped carbon atomization would be initiated and accelerated with the temperature rise, resulting in a gradually decreasing particle number of supported Pd NPs (Supplementary Fig. 14). The Pd NPs owning smaller sizes exhibited a strong tendency to vanish due to the quick loss of atoms. As shown in the marginal area of Fig. 2a, the marked Pd NP with a diameter of $5.5 \mathrm{~nm}$ (at $0 \mathrm{~s}$ ) was downsized to $4.8 \mathrm{~nm}$ at $16 \mathrm{~s}$ and to $2.6 \mathrm{~nm}$ at $30 \mathrm{~s}$, and finally vanished at $90 \mathrm{~s}$. This stems from the emission of surface Pd atoms and their continuous thermal diffusion within $\mathrm{N}$-doped carbon layers and trapped by the $\mathrm{N}$ coordination. As shown in Fig. 2b and Supplementary Fig. 15a, the isolated highdensity bright dots (highlighted by red circles) could be assigned to single-Pd atoms, demonstrating the migration of emitted Pd species within the $\mathrm{N}$-doped carbon layers. EDS mappings further revealed that the $\mathrm{Pd}, \mathrm{N}$, and $\mathrm{Ti}$ were homogeneously dispersed over the whole architecture. The detailed N-doped carbon atomization process was recorded by the in situ TEM (Supplementary Movie 1). After removing the carbon shells, these isolated Pd atoms were subsequently captured by $\mathrm{O}$ defects on $\mathrm{TiO}_{2}$ support, as confirmed by the isolated brighter dots (Fig. 2c, d; Supplementary Fig. 15b). The simulation image (Fig. 2e) obtained from 

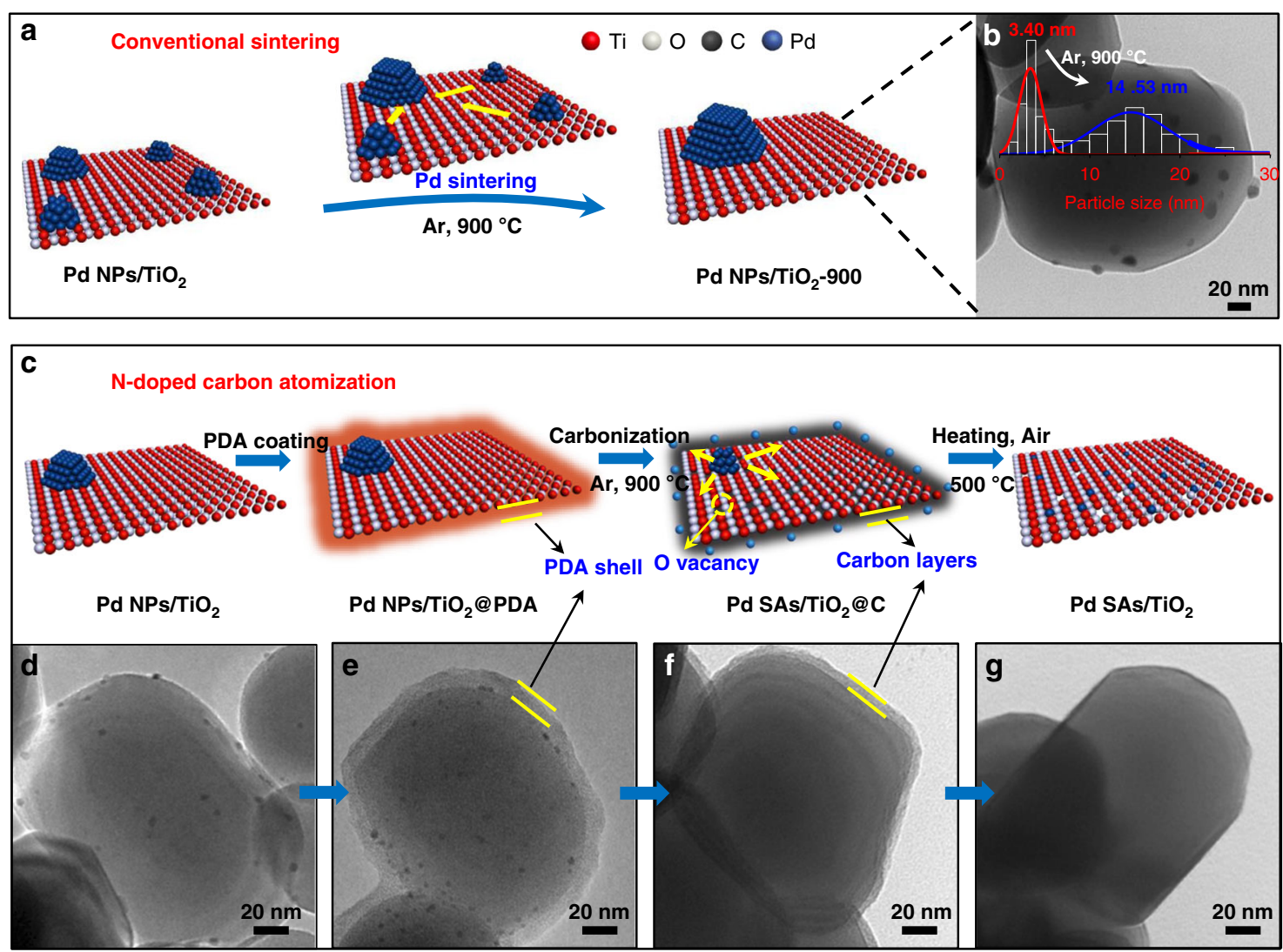

Fig. 1 Schematic illustrations and TEM images for the preparation of $\mathbf{P d} \mathbf{S A s} / \mathrm{TiO}_{\mathbf{2}}$ and reference materials. a Schematic images of the conventional sintering of $\mathrm{Pd} \mathrm{NPs} / \mathrm{TiO}_{2}$, which results in larger $\mathrm{Pd} \mathrm{NPs} / \mathrm{TiO}_{2}$ (denoted as $\mathrm{Pd} \mathrm{NPs} / \mathrm{TiO}_{2}-900$ ). $\mathbf{b} \mathrm{TEM}$ image of $\mathrm{Pd} \mathrm{NPs} / \mathrm{TiO}{ }_{2}-900$, in which the inset contains the particle-size distributions of $\mathrm{Pd} \mathrm{NPs} / \mathrm{TiO}_{2}$ (red line) and $\mathrm{Pd} \mathrm{NPs} / \mathrm{TiO}{ }_{2}-900$ (blue line). c Schematic images of the $\mathrm{N}$-doped carbon atomization of $\mathrm{Pd} \mathrm{NPs} / \mathrm{TiO}_{2}$, which results in $\mathrm{Pd} \mathrm{SAs} / \mathrm{TiO}_{2}$. TEM images of (d) initial Pd NPs/TiO, (e) Pd NPs/TiO $2 @ P D A,(\mathbf{f}) \mathrm{Pd} \mathrm{SAs} / \mathrm{TiO}{ }_{2} @ \mathrm{C}$, and (g) Pd SAs/TiO 2 . Scale bar, $20 \mathrm{~nm}$.

yellow rectangle in Fig. 2d and corresponding surface intensity profile (Fig. 2f) clearly showed the presence of Pd SAs, which is well consistent with the experimental STEM image. According to the Brunauer-Emmett-Teller (BET) and ICP-AES analysis (Supplementary Fig. 16, Supplementary Table 1), the surface coverage of Pd atoms in Pd SAs/ $/ \mathrm{TiO}_{2} @ \mathrm{C}$ and $\mathrm{Pd} \mathrm{SAs} / \mathrm{TiO}_{2}$ are estimated to be 0.58 and 1.14 atoms $\mathrm{nm}^{-2}$, respectively. Furthermore, the selected $\mathrm{Ti}-\mathrm{L}$ and $\mathrm{O}-\mathrm{K}$ electron energy-loss spectroscopy (EELS) spectra recorded at various positions in STEM image revealed the generation of $\mathrm{O}$ defects on $\mathrm{TiO}_{2}$ surface $^{35}$ (Supplementary Fig. 17). Also, the evolution from Pd NPs to Pd SAs in the annealing process was traced by extended X-ray absorption fine structure (EXAFS, Fig. 2g), during which the increased peak of $\mathrm{Pd}-\mathrm{N}$ and disappeared peak of $\mathrm{Pd}-\mathrm{Pd}$ indicated the transformation from Pd NPs to Pd SAs. Functional theory (DFT) calculations were performed to simulate this $\mathrm{N}$-doped carbon atomization (Supplementary Fig. 19). Furthermore, EXAFS was performed to further confirm that Pd species were atomically dispersed on the $\mathrm{TiO}_{2}$ support (Fig. $2 \mathrm{~g}$ ). The EXAFS spectra of Pd NPs $\left(\mathrm{Pd} \mathrm{NPs} / \mathrm{TiO}_{2}\right)$ displayed a peak $\sim 2.5 \AA$, which was attributed to $\mathrm{Pd}-\mathrm{Pd}$ bond. For Pd $\mathrm{SAs} / \mathrm{TiO}_{2}$, only one dominant peak around $1.5 \AA$ was observed, which can be assigned to $\mathrm{Pd}-\mathrm{O}$ bond. This verified the successful transformation from Pd NPs to SAs during the N-doped carbon atomization process.

X-ray diffraction (XRD) patterns (Fig. 3a) displayed that a characteristic peak $\left(2 \theta=\sim 40.3^{\circ}\right)$ of $\mathrm{Pd}(111)$ disappeared after the carbonization (from Pd NPs/TiO $@$ @PDA to Pd SAs/ $\mathrm{TiO}_{2} @ \mathrm{C}$ ), indicating the evolution from well-crystallized Pd NPs to atomic species. Also, no observable signal of Pd crystals can be found for Pd SAs/TiO as-prepared Pd SAs samples. Interestingly, the coated carbon layers would change the normal phase evolution from anatase to rutile $\mathrm{TiO}_{2}$ along with the temperature (Supplementary Figs. 20-22). DFT calculations (Fig. 3b) reveal the total energy difference $(\Delta E)$ of the two types $\mathrm{TiO}_{2}$ is $-1.44 \mathrm{eV}$, suggesting that the phase transition from anatase to rutile is an exothermic reaction. However, when the $\mathrm{N}$-doped $\mathrm{C}(\mathrm{NC})$ layer was coated on anatase $\mathrm{TiO}_{2}$, the phase transition exhibits an endothermicity reaction with a larger $\Delta E$ of $+6.00 \mathrm{eV}$, indicating that the phase transition of $\mathrm{TiO}_{2} @ \mathrm{NC}$ needs more external energy. These results demonstrate that the coated carbon layers can delay the process of phase transition effectively. X-ray photoelectron spectroscopy (XPS) was used to track the change of characteristic $\mathrm{O} 1 \mathrm{~s}$ peaks (Fig. 3c), which is ascribed to the Ti-O-Ti and O-vacancy ${ }^{19}$. A higher peak area at $532 \mathrm{eV}$ for Pd SAs/TiO $\mathrm{T}_{2} @ \mathrm{C}$ and $\mathrm{Pd} \mathrm{SAs} / \mathrm{TiO}_{2}$ with respect to the fresh supported samples demonstrated that more oxygen vacancies were constructed after annealing at high temperatures $\mathrm{S}^{36,37}$. This coincides well with the smaller optical band gap of $\mathrm{Pd} \mathrm{SAs} / \mathrm{TiO}_{2}(3.17 \mathrm{eV})$ than $\mathrm{Pd} \mathrm{NPs} / \mathrm{TiO}_{2}(3.24 \mathrm{eV})$, which was observed by UV-vis diffuse reflectance spectra (Supplementary Fig. 23). Furthermore, more detailed structural information can be obtained from the nearedge X-ray absorption fine structure (NEXAFS). The O $1 \mathrm{~s}(\mathrm{k}$ edge) NEXAFS of $\mathrm{Pd} \mathrm{NPs} / \mathrm{TiO}_{2}$ showed almost identical spectra to that of pure $\mathrm{TiO}_{2}$ (Supplementary Fig. 24a). Specifically, there were two strong bands $\left(t_{2 g}\right.$ and $\left.e_{g}\right)$ in the low-energy range of the spectra $(528-535 \mathrm{eV})$ for the oxygen $2 \mathrm{p}$ states that were hybridized with the empty split Ti $3 \mathrm{~d}_{\text {bands }}{ }^{38}$. As for the C, D, 

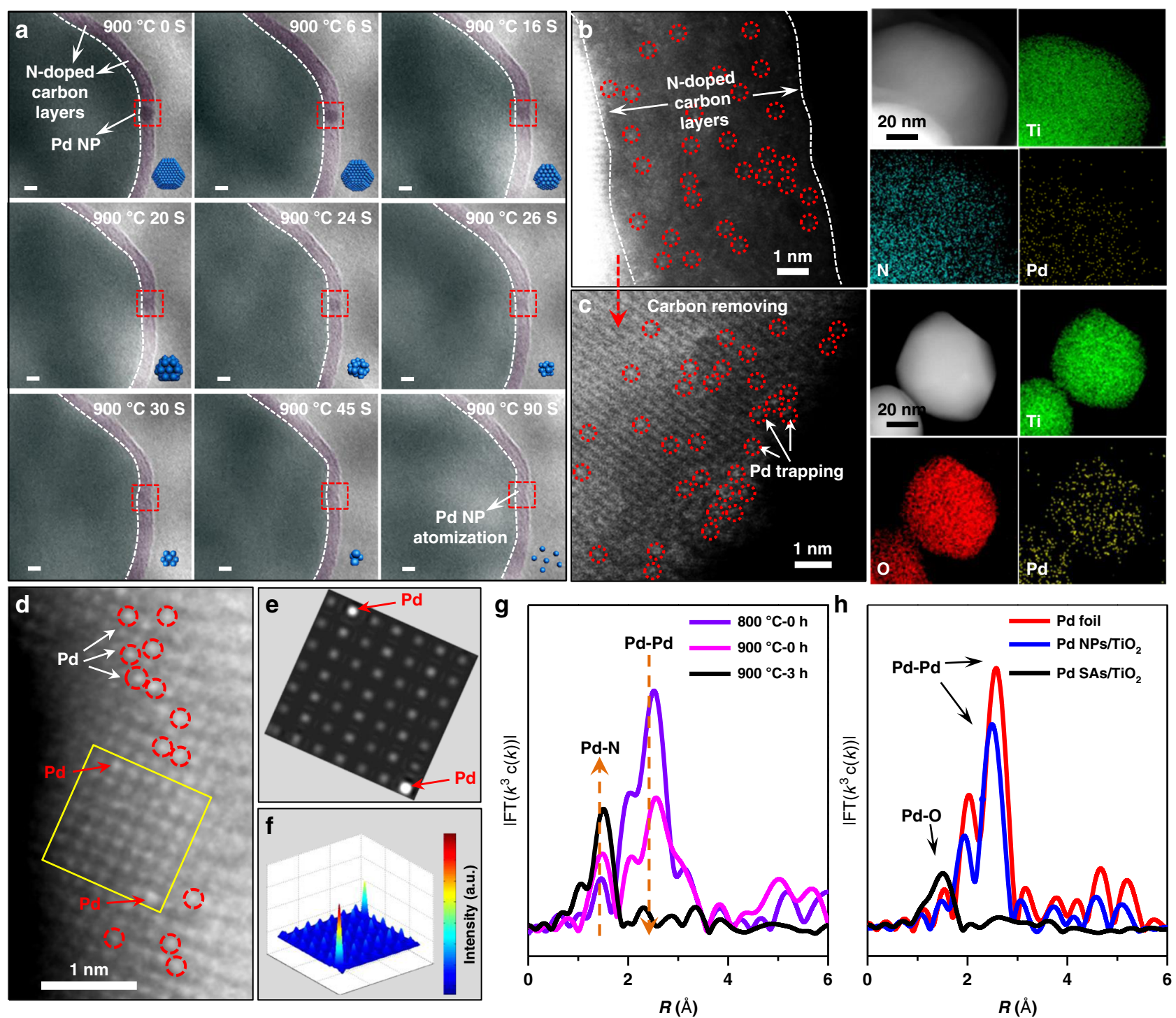

Fig. 2 NP-to-SA transformation of Pd and corresponding structural characterizations. a Representative movie images of Pd NPs/TiO ${ }_{2} @ C$ acquired at $900^{\circ} \mathrm{C}$ at different times with in situ TEM under Ar atmosphere. b, c Aberration-corrected HAADF-STEM images and EDS mapping images of Pd SAs/ $\mathrm{TiO}_{2} @ \mathrm{C}(\mathbf{b})$ and Pd SAs $/ \mathrm{TiO}_{2}$ (c). The HAADF image in (b) was taken from a region similar to the boxed one in (a). AC HAADF-STEM image (d) of Pd $\mathrm{SAs} / \mathrm{TiO}_{2}$ and the simulated image (e) obtained from the yellow rectangle in (d), and (f) the corresponding 3D surface intensity profile image. Some of the Pd SAs in the HAADF images of (b-d) are highlighted by red circles. $\mathbf{g}$ Fourier-transformed (FT) $\mathrm{k}^{3}$-weighted Pd K-edge EXAFS spectra for Pd NPs/ $\mathrm{TiO}_{2} @ \mathrm{PDA}$ during the annealing. $\mathbf{h}$ Fourier-transformed (FT) $\mathrm{k}^{3}$-weighted $\chi(\mathrm{k})$-function of the EXAFS spectra for $\mathrm{Pd} \mathrm{K}$-edge of Pd $\mathrm{SAs} / \mathrm{TiO}{ }_{2}$ and Pd NPs/ $\mathrm{TiO}_{2}$. Scale bar, $5 \mathrm{~nm}$ for (a), $1 \mathrm{~nm}$ for AC HAADF-STEM images in (b-d), $20 \mathrm{~nm}$ for mappings in (b, c).

and E peaks in the high-energy region, they were formed by the delocalized antibonding $\mathrm{O} 2 \mathrm{p}$ states and $\mathrm{Ti} 4 \mathrm{sp}$ band $^{39}$. For Pd $\mathrm{SAs} / \mathrm{TiO}_{2}$ (Fig. 3d), the intensity of the four peaks $\left(\mathrm{t}_{2 \mathrm{~g}}, \mathrm{e}_{\mathrm{g}}, \mathrm{C}\right.$, and D) were lower, and the $\mathrm{E}$ peak was absent. These suggest that the $\mathrm{N}$-doped carbon atomization can create defects on the surface of supports. Supplementary Fig. 24b and c showed Ti 2p (L-edge) NEXAFS spectra of Pd NPs/TiO 2 , Pd SAs/TiO 2 , and pure $\mathrm{TiO}_{2}$ samples. There were two bands $\left(\mathrm{L}_{3}\right.$ and $\left.\mathrm{L}_{2}\right)$ existing in each sample, presumably due to the $2 \mathrm{p}$ spin-orbit coupling ${ }^{38}$. In addition, $\mathrm{L}_{3}$ and $\mathrm{L}_{2}$ further split into $t_{2 \mathrm{~g}}$ and $e_{\mathrm{g}}$ as a consequence of the low symmetry of the $\mathrm{TiO}_{6}{ }^{8-}$ ligand field $\mathrm{O}_{\mathrm{h}}\left(\right.$ ref. $\left.{ }^{38}\right)$. One small difference was visible for $\mathrm{Pd} \mathrm{SAs} / \mathrm{TiO}_{2}$ : the L-edge absorption onset demonstrated a smaller red-shift than those of others, providing a preliminary evidence of a $\mathrm{Ti}$ oxidation state $(<+4)$ and the presence of oxygen vacancies near $\mathrm{Ti}$ atoms ${ }^{19,40}$. Electron paramagnetic resonance (EPR) spectrum of $\mathrm{Pd} \mathrm{SAs} / \mathrm{TiO}_{2}$ showed a prominent peak at 2.003 correspond to single electron-trapped oxygen vacancies, further suggesting the $\mathrm{O}$ defects in Pd SAs/TiO 2 (Supplementary Fig. 25). The NEXAFS spectrometry of $\mathrm{Pd} \mathrm{SAs} / \mathrm{TiO}_{2}$ in Fig. 3e showed near-edge absorption energy more positive than those of $\mathrm{Pd} \mathrm{NPs} / \mathrm{TiO}_{2}$ and $\mathrm{Pd}$ foil, implying that the $\mathrm{Pd}$ single atoms carried positive charges. Also, by the XPS measurements, the binding energy of $\mathrm{Pd} 3 \mathrm{~d}_{5 / 2}$ peak at $336.5 \mathrm{eV}$ for $\mathrm{Pd} \mathrm{SAs} / \mathrm{TiO}_{2}$ was higher than that of $\mathrm{Pd}^{0}(335.3 \mathrm{eV})$ for $\mathrm{Pd} \mathrm{NPs} / \mathrm{TiO}_{2}$, suggesting the ionic $\mathrm{Pd}^{\delta+}(0$ $<\delta$ ) nature of $\mathrm{Pd}$ in $\mathrm{Pd} \mathrm{SAs} / \mathrm{TiO}_{2}$ (Supplementary Fig. 26). Quantitative analysis of $\mathrm{Pd} \mathrm{SAs} / \mathrm{TiO}_{2}$ and $\mathrm{Pd} \mathrm{NPs} / \mathrm{TiO}_{2}$ were carried out through least-square EXAFS fitting. The fitting curves are displayed in Supplementary Figs. 27-29, and the corresponding structure parameters are listed in Supplementary Table 2. The first coordination number of the central atom Pd is about three and the average bond length of $\mathrm{Pd}-\mathrm{O}$ is 1.97 , whereas the coordination number of Pd NPs is about 9.7 and the bond length is 2.72 , similar to those of Pd foil. 
a
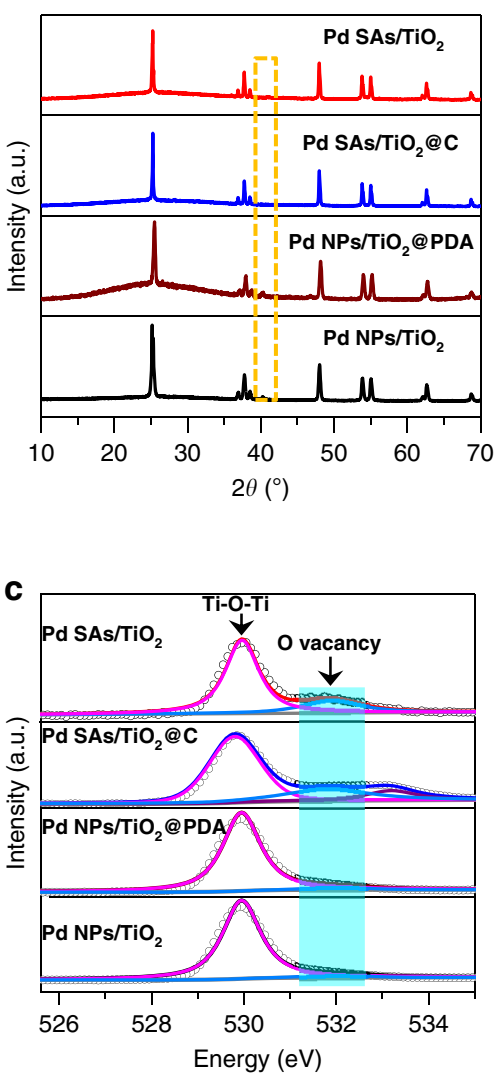

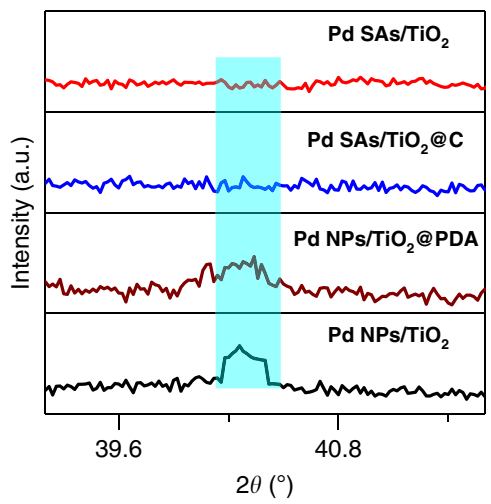

b
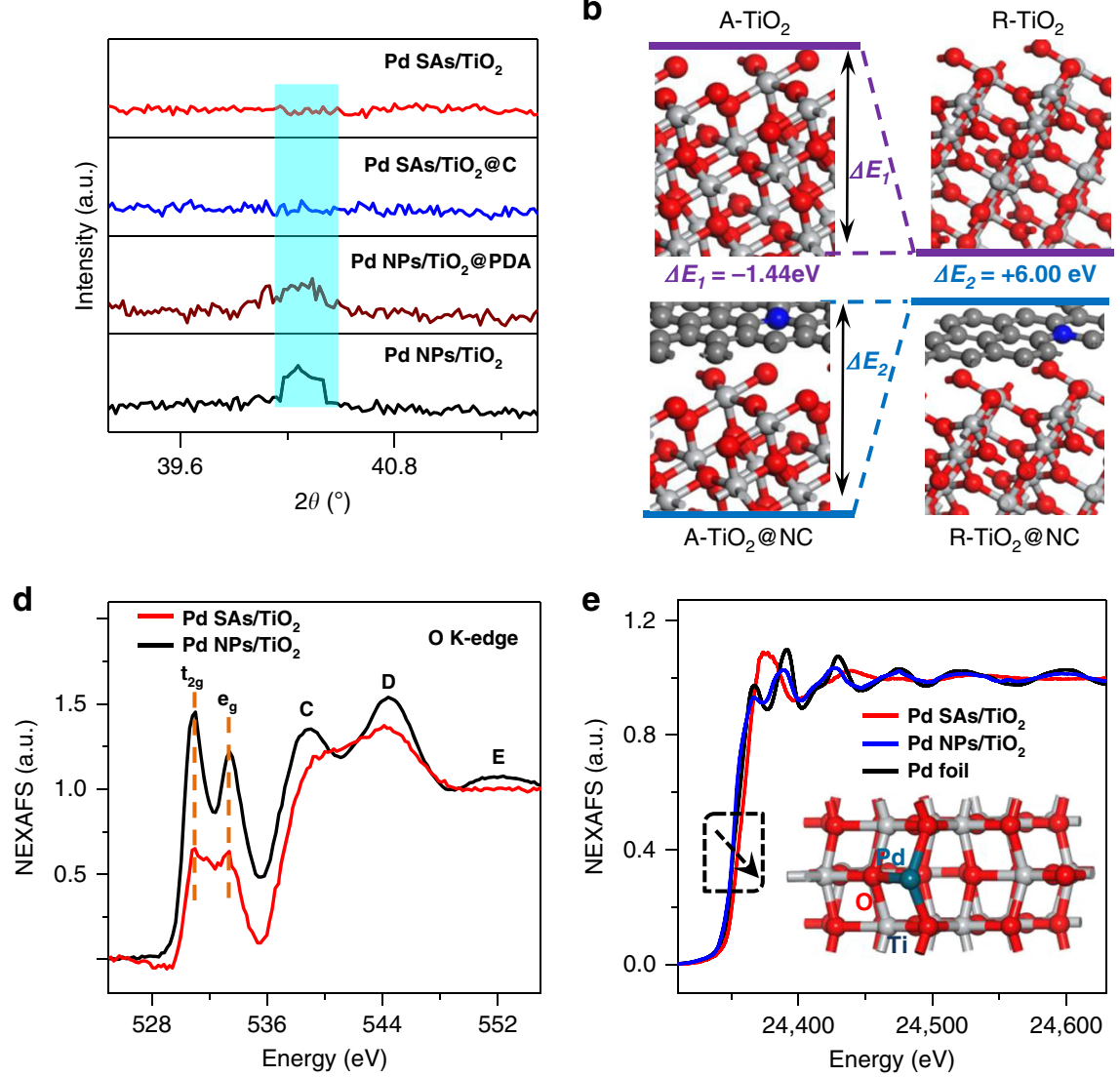

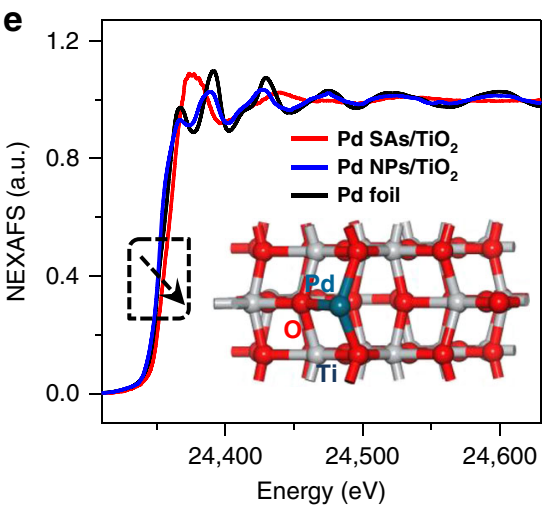

Fig. 3 Structural characterizations of $\mathbf{P d} \mathbf{S A s} / \mathrm{TiO}_{\mathbf{2}}$ and reference materials. a XRD patterns. $\mathbf{b}$ Structure configurations and the energy difference of/ between anatase $\mathrm{TiO}_{2}\left(\mathrm{~A}-\mathrm{TiO}_{2}\right)$ and rutile $\mathrm{TiO}_{2}\left(\mathrm{R}-\mathrm{TiO}_{2}\right)$, anatase $\mathrm{TiO}_{2} @ \mathrm{~N}$-doped carbon $\left(\mathrm{A}-\mathrm{TiO}_{2} @ \mathrm{NC}\right)$ and rutile TiO $\mathrm{T}_{2} @ \mathrm{~N}-$ doped carbon $\left(\mathrm{R}-\mathrm{TiO} \mathrm{O}_{2} @ \mathrm{NC}\right)$. Silver white atoms represent $\mathrm{Ti}$, red atoms represent $\mathrm{O}$, gray atoms represent $\mathrm{C}$ and blue atoms represent $\mathrm{N}$. c XPS spectra for samples during each synthetic step of $\mathrm{N}$-doped $\mathrm{C}$ atomization. d O K-edge and e Pd K-edge NEXAFS spectra of $\mathrm{Pd} \mathrm{SAs} / \mathrm{TiO}_{2}$ and $\mathrm{Pd} \mathrm{NPs} / \mathrm{TiO}_{2}$. Inset is the proposed $\mathrm{Pd}-\mathrm{O}_{3}$ architectures.

Hydrogenation reactions were subsequently conducted to further confirm the presence of atomically dispersed Pd species. As shown in Fig. 4a and Supplementary Fig. 30, the pure $\mathrm{TiO}_{2}$ showed $<1 \%$ styrene conversion to phenylethane after $125 \mathrm{~min}$ of reaction. However, the $\mathrm{Pd} \mathrm{SAs} / \mathrm{TiO}_{2}$ delivered over $99 \%$ conversion during the same time span, indicating the highly active $\mathrm{Pd}$ species. With comparable metal loading, the $\mathrm{Pd} \mathrm{NPs} / \mathrm{TiO}_{2}-900$ delivered only $43 \%$ conversion, inferior to fresh $\mathrm{Pd} \mathrm{NPs} / \mathrm{TiO}_{2}$ (59\%), revealing the activity loss caused by conventional thermal sintering. The specific reactivity (SR) for the prepared Pd species samples was further calculated to compare catalytic efficiency. As shown in Fig. 4b, the SR value of Pd SAs/TiO 2 (1292 moles of styrene per mole of palladium per hour) was greater than those $\mathrm{Pd} \mathrm{NPs} / \mathrm{TiO}_{2}$ by a factor of $1.8, \mathrm{Pd} \mathrm{NPs} / \mathrm{TiO}_{2}-900$ by a factor of 2.6 , and $\mathrm{Pd} / \mathrm{C}$ by a factor of 5.3 , revealing the highest catalytic efficiency. Furthermore, another hydrogenation reaction of nitrobenzene also confirmed that the $\mathrm{Pd} \mathrm{SAs} / \mathrm{TiO}_{2}$ could reach a higher reaction rate than $\mathrm{Pd} \mathrm{NPs} / \mathrm{TiO}_{2}-900$. As shown in Supplementary Fig. 32, the $\mathrm{Pd} \mathrm{SAs} / \mathrm{TiO}_{2}$ showed a $>99 \%$ nitrobenzene conversion in $150 \mathrm{~min}$, whereas $\mathrm{Pd} \mathrm{NPs} / \mathrm{TiO}_{2}-900$ exhibited only $29 \%$ conversion under identical condition. Figure $4 \mathrm{c}$ and Supplementary Fig. 33 exhibited that the catalytic activity and reaction rate of $\mathrm{Pd} \mathrm{SAs} / \mathrm{TiO}_{2}$ were maintained even after ten cycles, suggesting the robust nature of the atomically dispersed $\mathrm{Pd} \mathrm{SAs} / \mathrm{TiO}_{2}$. As shown in the aberration-corrected HAADF-STEM and EXAFS images (Supplementary Fig. 34), the Pd species remained atomically dispersed after ten catalytic cycles. These results indicated that the atomically dispersed Pd species were strongly bounded to defective $\mathrm{TiO}_{2}$ through $\mathrm{N}$ doped carbon atomization, and they exhibited excellent chemical and thermal stability. Furthermore, we used $\mathrm{Fe}^{3+}$ solution to etch the supported $\mathrm{Pd}$ species of $\mathrm{Pd} \mathrm{SAs} / \mathrm{TiO}_{2}$ and $\mathrm{Pd} \mathrm{NPs} / \mathrm{TiO}_{2}$ through an oxidative process ${ }^{41}$. The $\mathrm{Pd} \mathrm{SAs} / \mathrm{TiO}_{2}$ treated by $\mathrm{Fe}^{3+}$ solution exhibited only $\sim 8 \%$ decrease in activity (Supplementary Fig. 35), indicating the robustness of atomically dispersed Pd species. By contrast, as evidenced by TEM image (Supplementary Fig. 36), the $\mathrm{Fe}^{3+}$ solution could etch nearly all of the supported Pd NPs for Pd NPs/TiO 2 , accompanied by a heavy activity loss (Supplementary Fig. 35).

To further study the activity and stability of the obtained $\mathrm{Pd}$ SAs, their catalytic performance was studied by the diphenylmethylsilane oxidation with water. As a result, the conversion of silane to silanol was $>99 \%$ after 50 min catalysis reaction by atomically dispersed $\mathrm{Pd}$ species ( $\left.\mathrm{Pd} \mathrm{SAs} / \mathrm{TiO}_{2}\right)$, while $18 \%$ conversion was delivered by supported Pd NPs with the same Pd loading (Supplementary Fig. 37). Importantly, no other products, i.e., siloxanes, were detected during the reaction catalyzed by $\mathrm{Pd}$ $\mathrm{SAs} / \mathrm{TiO}_{2}$. Moreover, the Pd SAs also delivered an excellent stability and selectivity (>99\%) throughout a five cycles recycling test. Similar results can be obtained by applying Pd SAs to catalyze hydrosilylation of 1-octene as a model substrate with triethoxysilane $\left((\mathrm{EtO})_{3} \mathrm{SiH}\right)$. As shown in Supplementary Fig. 38, the $\mathrm{Pd} \mathrm{SAs} / \mathrm{TiO}_{2}$ exhibited an excellent selectivity of $>98 \%$ toward anti-Markovnikov addition product of triethoxy(octyl)silane with a conversion of $>99 \%$ within $3 \mathrm{~h}$. In comparison, the conversion catalyzed by supported Pd NPs reached only $32 \%$. In addition, the 
a

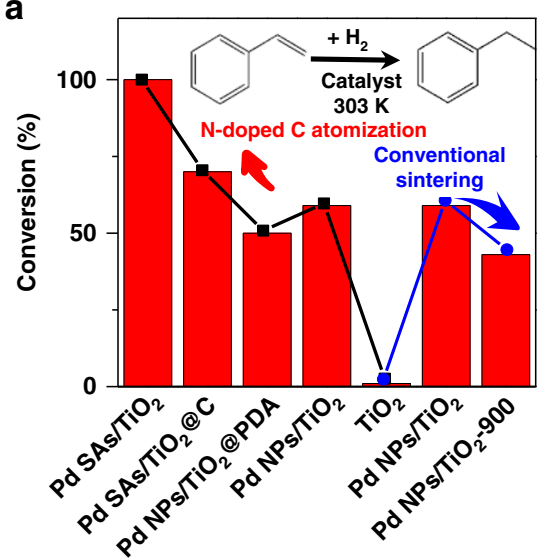

b

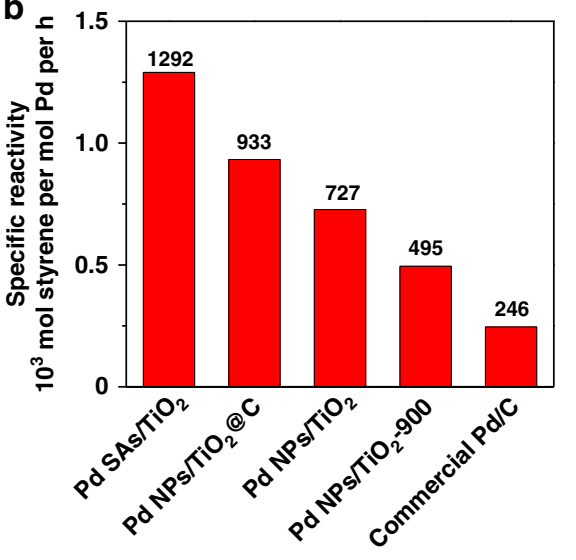

C

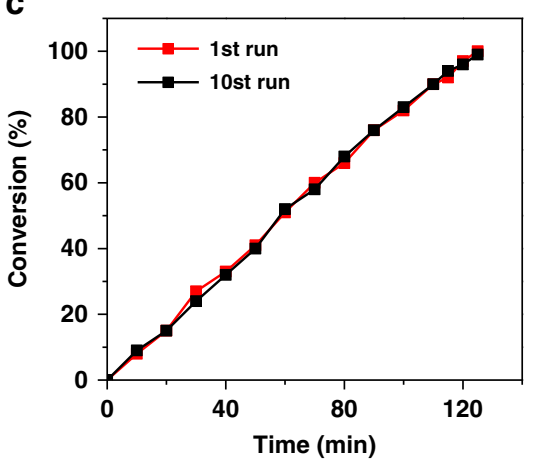

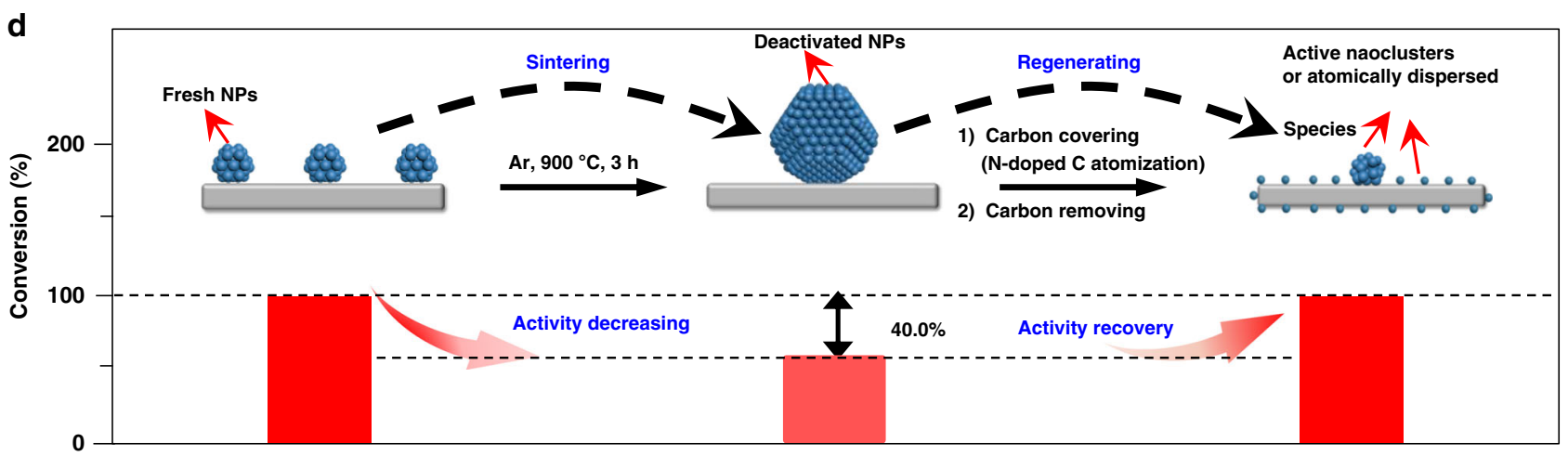

e

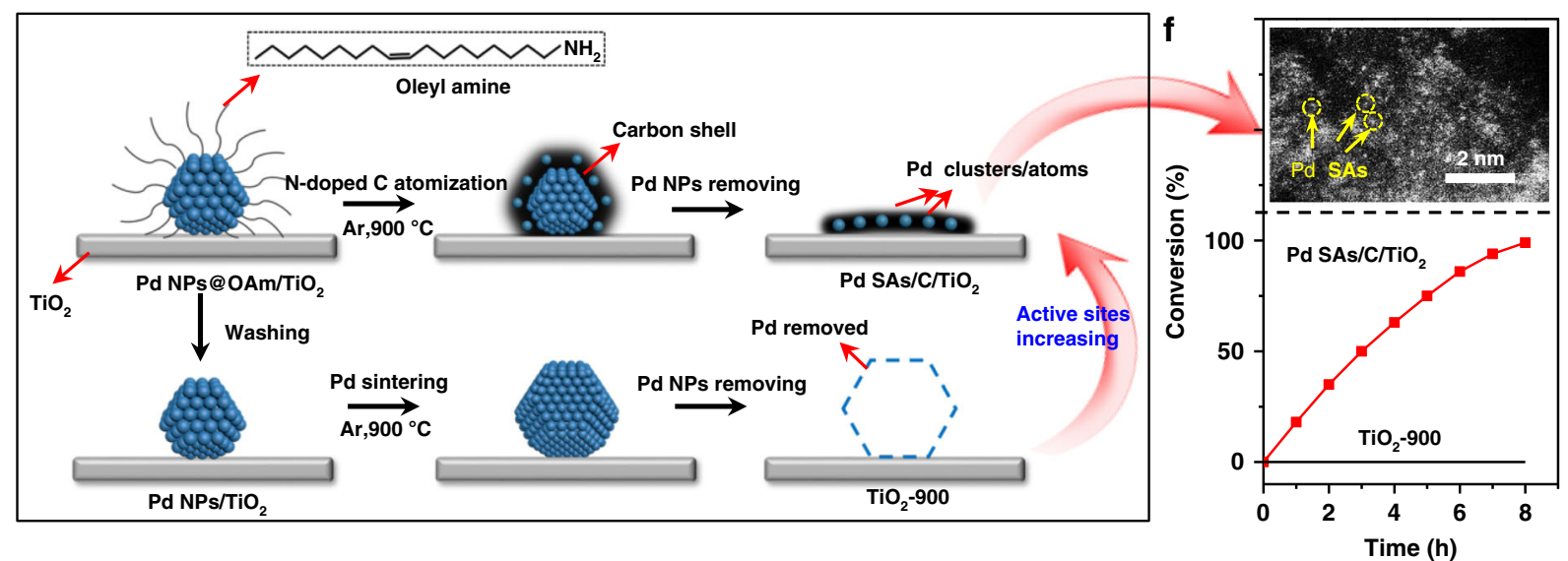

Fig. 4 Catalytic performances and schematic illustrations of Pd SAs and Pd NPs. a Catalytic performance for fresh $\mathrm{TiO}_{2}$ and catalysts prepared by Ndoped $\mathrm{C}$ atomization and conventional sintering in styrene hydrogenation. b Specific reactivity of $\mathrm{Pd} \mathrm{SAs} / \mathrm{TiO}_{2}$ and the reference catalysts. c Catalytic stability of $\mathrm{Pd} \mathrm{SAs} / \mathrm{TiO}_{2}$. d Schematic images (top) of the formation of deactivated NPs and active nanoclusters or atomic species. Catalytic performance (bottom) of $\mathrm{Pd} \mathrm{NPs} / \mathrm{TiO}_{2}, \mathrm{Pd} \mathrm{NPs} / \mathrm{TiO}_{2}-900$ and $\mathrm{Pd} \mathrm{NPs} / \mathrm{TiO}_{2}-900$ after treatment by $\mathrm{N}$-doped $\mathrm{C}$ atomization process (denoted as $\mathrm{Pd} \mathrm{SAs/NPs/TiO}{ }_{2}^{-}$ 900) in styrene hydrogenation for $3.5 \mathrm{~h}$. e Schematic images of the formation of $\mathrm{Pd} \mathrm{SAs} / \mathrm{C} / \mathrm{TiO}_{2}$ by $\mathrm{N}$-doped $\mathrm{C}$ atomization process (by using $\mathrm{Pd}$ $\mathrm{NPs} @ \mathrm{OAm} / \mathrm{TiO}_{2}$ as precursors) and $\mathrm{TiO}_{2}-900$ by conventional sintering (by using Pd NPs/ $/ \mathrm{TiO}_{2}$ as precursors). f AC HAADF-STEM image of Pd SAs/C/ $\mathrm{TiO}_{2}$ and its catalytic performance. Scale bar, $2 \mathrm{~nm}$.

activity and selectivity of the single-Pd atom catalyst was maintained (Supplementary Fig. 38). Overall, the above reactions all demonstrated that a type of more active and selective Pd SAs was generated by this $\mathrm{N}$-doped carbon atomization process, compared with the initial supported Pd NPs catalyst.

Moreover, by our developed strategy, a severely sintered and deactivated Pd NPs catalyst could be reactivated by downsizing the supported Pd NPs and regenerating the more active atomically dispersed Pd species (Fig. 4d). TEM and HAADF-STEM images in Supplementary Figs. 2, 39, 40 showed that the sintered Pd NPs supported on $\mathrm{TiO}_{2}$ with an average size of $14.53 \mathrm{~nm}$ could be cut down to $\sim 2 \mathrm{~nm}$. This process also generated abundant atomically dispersed Pd sites (as verified by XRD, STEM and EXAFs images in Supplementary Figs. 40, 41). With comparable Pd loading, the conversion of sintered Pd NPs catalyst $(60 \%$ in $3.5 \mathrm{~h}$ for hydrogenation reaction) could be recovered to $>99 \%$ after the $\mathrm{N}$-doped carbon atomization (Fig. $4 \mathrm{~d}$ ), accompanied by the specific reactivity recovery (from $525 \mathrm{~h}^{-1}$ to $756 \mathrm{~h}^{-1}$, Supplementary Fig. 42).

It is deduced that the $\mathrm{N}$-doped carbon atomization is a more general phenomenon that can exist in various supported metal 
$(\mathrm{Pd}, \mathrm{Au}, \mathrm{Pt})$ catalysts containing nitrogen ingredients. Similarly, small $\mathrm{Au} / \mathrm{Pt} \mathrm{NPs}$ could also be successful transformed into atomically dispersed $\mathrm{Au} / \mathrm{Pt}$ sites due to the strong $\mathrm{N}$ coordination and trapped by $\mathrm{O}$ defects on $\mathrm{TiO}_{2}$ surface (Supplementary Figs. 43, 44). They have been studied as well, and will be presented in a subsequent paper. Also, Pd NPs with and without oleylamine $(\mathrm{OAm})$ coating were prepared and supported on $\mathrm{TiO}_{2}$ (Fig. 4e; Supplementary Figs. 45-47). Followed by pyrolysis at $900{ }^{\circ} \mathrm{C}$, the OAm shells would be transformed in situ to N-doped carbon, which would provide the atomic diffusion sites for the migration of atomic $\mathrm{Pd}$ species at high temperatures (as demonstrated by inset AC HAADF-STEM images in Fig. 4f and Supplementary Fig. 48). Etched by the $\mathrm{Fe}^{3+}$ solution, the Pd NPs without the protection of OAm were successfully removed, leaving an inert $\mathrm{TiO}_{2}$ support. Interestingly, the etched OAmcapped Pd catalyst was still active for the hydrogenation reactions, demonstrating the generation of the active and stable atomically dispersed $\mathrm{Pd}$ residues (Fig. 4f).

\section{Discussion}

In summary, we discovered an unusual transformation process from Pd NPs to more active atomically dispersed Pd species through $\mathrm{N}$-doped carbon atomization. Our findings unravel the connection between nanoscale and atomic-scale species at high temperatures. This may also open an avenue for preparing sinterresistant single-metal atoms for various applications or recovering the sintered and deactivated industrial supported metal catalysts.

\section{Methods \\ Chemicals. All chemicals were used as received without further purification. Sodium hydrate $(\mathrm{NaOH})$, ethanol, toluene, acetone, hexane, ferric chloride $\left(\mathrm{FeCl}_{3} \cdot 6 \mathrm{H}_{2} \mathrm{O}\right)$, tris(hydroxymethyl) aminomethane, styrene, nitrobenzene, resor- cino, formaldehyde, and sodium carbonate were purchased from purchased from Sinopharm Chemical Reggent Co., Ltd. Dopamine-HCl was purchased from Beijing HWRK Chem Co., Ltd. $\mathrm{TiO}_{2}$ was purchased from Shanghai Macklin Biochemical Co., Ltd. Sodium tetrachloropalladate(II) $>=99.99 \%$ trace metals basis $\left(\mathrm{Na}_{2} \mathrm{PdCl}_{4}\right), \mathrm{Pd}(\mathrm{acac})_{2}(34.7 \%)$, chloroauric acid $\left(\mathrm{HAuCl}_{4} \cdot 4 \mathrm{H}_{2} \mathrm{O}\right)$, Potassium hexachloroplatinate, $40 \% \mathrm{Pt}\left(\mathrm{K}_{2} \mathrm{PtCl}_{6}\right)$ oleylamine $(\mathrm{OAm})$, acetic acid, and borane tributylamine complex (BTB) were purchased from Sigma-Aldrich. Triethox- ysilane, diphenylmethylsilane, and 1-Octene were purchased from TCI. Deionized water was used throughout this study.}

Preparation of Pd NPs/TiO $\mathbf{2}$. First, $20 \mathrm{mg}$ of $\mathrm{Na}_{2} \mathrm{PdCl}_{4}$ was added in $60 \mathrm{~mL}$ of $\mathrm{H}_{2} \mathrm{O}$ in a vial and sonicated for $30 \mathrm{~min}$. After heating at $70^{\circ} \mathrm{C}, 1 \mathrm{~g}$ of $\mathrm{TiO}_{2}$ was added, and the slurry was magnetically stirred for $12 \mathrm{~h}$. The suspension was separated by centrifugation and dried at $60^{\circ} \mathrm{C}$ under vacuum and then calcined at $300^{\circ} \mathrm{C}$ in Ar for $2 \mathrm{~h}$

Preparation of Pd NPs/TiO $\mathbf{2}_{\mathbf{2}} @$ PDA. The pre-synthesized Pd NPs/TiO $(500.0 \mathrm{mg}$ ) were dispersed by ultrasound in $200.0 \mathrm{~mL}$ of freshly prepared Tris buffer solution (10 mM, pH 8.5). Then $20.0 \mathrm{~mL}$ of dopamine- $\mathrm{HCl}(300.0 \mathrm{mg})$ solution was added to the buffer solution ${ }^{42}$. The mixed solution was allowed to stir for $12 \mathrm{~h}$ at room temperature. The resulting products were washed with deionized water and ethanol three times, and collected by centrifugation. After dried at $70{ }^{\circ} \mathrm{C}$ in a vacuum, the desired Pd NPs/TiO, @PDA was obtained.

Preparation of Pd SAs/TiO $\mathbf{2} @ \mathbf{C}$. In a typical procedure, the Pd $\mathrm{NPs} / \mathrm{TiO}_{2} @ \mathrm{PDA}$ power was transferred into a ceramic boat and placed in a tube furnace. The sample was annealed at $900^{\circ} \mathrm{C}$ for $3 \mathrm{~h}$ under $\mathrm{Ar}$ atmosphere with a heating rate of $5^{\circ} \mathrm{C} \mathrm{min}{ }^{-1}$. The obtained materials were denoted as $\mathrm{Pd} \mathrm{SAs} / \mathrm{TiO}_{2} @ \mathrm{C}$.

Preparation of $\mathbf{P d} \mathbf{S A s} / \mathrm{TiO}_{2}$. The $\mathrm{Pd} \mathrm{SAs} / \mathrm{TiO}_{2}$ were synthesized by directly heating the $\mathrm{Pd} \mathrm{SAs} / \mathrm{TiO}_{2} @ \mathrm{C}$ in air at $500{ }^{\circ} \mathrm{C}$ for $2 \mathrm{~h}$ with a ramp rate of $5{ }^{\circ} \mathrm{C} \mathrm{min}$ m $^{-1}$ before cooled down to room temperature naturally.

Preparation of $\mathbf{A u} / \mathbf{P t ~ S A s} / \mathrm{TiO}_{2}$. The synthetic procedure of $\mathrm{Au} / \mathrm{Pt} \mathrm{SAs} / \mathrm{TiO}_{2}$ was similar to Pd SAs/TiO 2 , except for using $10 \mathrm{mg}$ of $\mathrm{HAuCl}_{4} \cdot 4 \mathrm{H}_{2} \mathrm{O}$ or $20 \mathrm{mg}$ of $\mathrm{K}_{2} \mathrm{PtCl}_{6}$ to replace $20 \mathrm{mg}$ of $\mathrm{Na}_{2} \mathrm{PdCl}_{4}$. Also, Au/Pt NPs/TiO @PDA was annealed at $1000{ }^{\circ} \mathrm{C}$ for $6 \mathrm{~h}$ under $\mathrm{Ar}$ atmosphere to obtained $\mathrm{Au} / \mathrm{Pt} \mathrm{SAs} /$ $\mathrm{TiO}_{2} \mathrm{TiO}_{2} @ \mathrm{C}$
Preparation of $\mathbf{P d} \mathbf{N P s} / \mathrm{TiO}_{\mathbf{2}}-\mathbf{9 0 0}$. The synthetic procedure of $\mathrm{Pd} \mathrm{NPs} / \mathrm{TiO}_{2}-900$ was similar to Pd SAs/TiO $@$ @, except for using $\mathrm{Pd} \mathrm{NPs} / \mathrm{TiO}_{2}$ as precursors instead of Pd NPs/TiO $@$ @PDA.

Preparation of Pd SAs/NPs/TiO $\mathbf{2}-\mathbf{9 0 0}$. The synthetic procedure of Pd SAs/NPs/ $\mathrm{TiO}_{2}-900$ was similar to $\mathrm{Pd} \mathrm{SAs} / \mathrm{TiO}_{2}$, except for using $\mathrm{Pd} \mathrm{NPs} / \mathrm{TiO}_{2}-900$ as precursors instead of Pd NPs/TiO .

Preparation of $\mathrm{Fe}^{3+}$ treated-Pd NPs/TiO ${ }_{2}-900$ and $\mathrm{Fe}^{3+}$ treated-Pd SAs/ $\mathrm{TiO}_{2} \cdot \mathrm{Fe}^{3+}$ treated-Pd NPs/TiO $2-900$ and $\mathrm{Fe}^{3+}$ treated-Pd SAs/ $/ \mathrm{TiO}_{2}$ catalysts were obtained by dispersing $\mathrm{Pd} \mathrm{NPs} / \mathrm{TiO}_{2}-900$ and $\mathrm{Pd} \mathrm{SAs} / \mathrm{TiO}_{2}$ in an aqueous solution containing $\mathrm{FeCl}_{3}$ and $\mathrm{HCl}(\mathrm{pH}=0.55)^{41}$. In a standard procedure, $300 \mathrm{mg}$ of $\mathrm{KBr}$ $30 \mathrm{mg}$ of $\mathrm{FeCl}_{3} \cdot 6 \mathrm{H}_{2} \mathrm{O}, 0.18 \mathrm{~mL}$ of $\mathrm{HCl}$, and $7 \mathrm{~mL}$ of DI water were mixed in a glass vial. The mixture was heated to $100{ }^{\circ} \mathrm{C}$ in an oil bath under magnetic stirring. Subsequently, $20 \mathrm{mg}$ of $\mathrm{Pd} \mathrm{NPs} / \mathrm{TiO}_{2}-900$ or $\mathrm{Pd} \mathrm{SAs} / \mathrm{TiO}_{2}$ in $2 \mathrm{~mL}$ of $\mathrm{H}_{2} \mathrm{O}$ was added. After stirring for $3 \mathrm{~h}$, the product was collected by centrifugation, washed twice with ethanol and three times with water. After dried at $70{ }^{\circ} \mathrm{C}$ in a vacuum, the product was obtained.

Preparation of Pd NPs@OAm. The synthetic route of Pd SAs/CN/TiO was followed the method reported by Sun's group ${ }^{43}$. In typically, under a nitrogen flow, $75 \mathrm{mg}$ of $\mathrm{Pd}(\mathrm{acac})_{2}$ was mixed in $15 \mathrm{~mL}$ of oleylamine $(\mathrm{OAm})$. The formed solution was heated to $60^{\circ} \mathrm{C}$ in $10 \mathrm{~min}$, resulting in anear colorless solution. In all, $300 \mathrm{mg}$ of borane tributylamine complex (BTB) was solvated in OAm $(\sim 3-4 \mathrm{~mL})$, and quickly injected into the Pd-OAm solution. The color of solution was changed into brownblack immediately. The as-obtained solution was heated to $90^{\circ} \mathrm{C}\left(3{ }^{\circ} \mathrm{C} / \mathrm{min}\right)$, and kept at $90^{\circ} \mathrm{C}$ for $60 \mathrm{~min}$. The solution was cooled down to room temperature. The product was separated by centrifugation ( $8000 \mathrm{rpm}$ for $8 \mathrm{~min}$ ). Eventually, the product was dispersed in hexane with a concentration of $1.5 \mathrm{mg} / \mathrm{mL}$.

Preparation of Pd NPs@OAm/TiO persed into above-mentioned Pd NPs@OAm solution $(20 \mathrm{~mL})$. Then, the resulting colloidal mixture was sonicated for $6 \mathrm{~h}$ (to ensure complete adherence of $\mathrm{Pd}$ NPs@OAm onto $\mathrm{TiO}_{2}$ support). After evaporation of hexane, the Pd NPs@OAm/ $\mathrm{TiO}_{2}$ was obtained.

Preparation of $\mathbf{P d} \mathbf{N P s} / \mathbf{C} / \mathrm{TiO}_{2}$. The synthetic procedure of $\mathrm{Pd} \mathrm{NPs} / \mathrm{CN} / \mathrm{TiO}$, was similar to Pd SAs/TiO $@$ C, except for using Pd NPs@OAm/ $/ \mathrm{TiO}_{2}$ as precursors instead of Pd NPs/TiO 2 @PDA.

Preparation of $\mathbf{P d ~ S A s} / \mathbf{C} / \mathrm{TiO}_{2}$. $\mathrm{Pd} \mathrm{SAs} / \mathrm{C} / \mathrm{TiO}_{2}$ was prepared by removing the $\mathrm{Pd} \mathrm{NPs}$ of $\mathrm{Pd} \mathrm{NPs} / \mathrm{C} / \mathrm{TiO}_{2}$ using an aqueous solution containing $\mathrm{FeCl}_{3}$ and $\mathrm{HCl}$ $(\mathrm{pH}=0.55)$. In a standard procedure, $300 \mathrm{mg}$ of $\mathrm{KBr}, 30 \mathrm{mg}$ of $\mathrm{FeCl}_{3} \cdot 6 \mathrm{H}_{2} \mathrm{O}$, $0.18 \mathrm{~mL}$ of $\mathrm{HCl}$, and $7 \mathrm{~mL}$ of DI water were mixed in a glass vial. The mixture was heated to $100^{\circ} \mathrm{C}$ in an oil bath under magnetic stirring. Subsequently, $40 \mathrm{mg} \mathrm{Pd}$ $\mathrm{NPs} / \mathrm{C} / \mathrm{TiO}_{2}$ was added. After stirring for $3 \mathrm{~h}$, the product was collected by centrifugation, washed twice with ethanol and three times with water. After dried at $70{ }^{\circ} \mathrm{C}$ in a vacuum, the $\mathrm{Pd} \mathrm{SAs} / \mathrm{C} / \mathrm{TiO}_{2}$ was obtained.

Preparation of Pd NPs/TiO 2 without OAm. In all, $10 \mathrm{~mL}$ of acetic acid was added to $40 \mathrm{mg}$ of Pd NPs@OAm/ $/ \mathrm{TiO}_{2}$ in $50 \mathrm{~mL}$ of hexane dispersion and heated at $70^{\circ} \mathrm{C}$ for $10 \mathrm{~h}$. Then the mixture was cooled down to room temperature. In total, $30 \mathrm{~mL}$ of ethanol was added, and the mixture was centrifuged at $8000 \mathrm{rpm}$ for $8 \mathrm{mins}$. This procedure was repeated twice. After dried at $70{ }^{\circ} \mathrm{C}$ in a vacuum, the $\mathrm{Pd} N \mathrm{NP} / \mathrm{TiO}_{2}$ was obtained.

Preparation of $\mathbf{T i O}_{\mathbf{2}}-\mathbf{- 9 0 0}$. The synthetic procedure of $\mathrm{TiO}_{2}-900$ was similar to $\mathrm{Pd}$ $\mathrm{SAs} / \mathrm{C} / \mathrm{TiO}_{2}$, except for using $\mathrm{Pd} \mathrm{NPs} / \mathrm{TiO}_{2}$ without $\mathrm{OAm}$ as precursor instead of $\mathrm{Pd} \mathrm{NPs@OAm/TiO}$

Preparation of $\mathbf{P d} \mathbf{N P s} / \mathrm{TiO}_{\mathbf{2}}-\mathbf{H}_{\mathbf{2}}$. In total, $20 \mathrm{mg}$ of $\mathrm{Na}_{2} \mathrm{PdCl}_{4}$ was added in $60 \mathrm{~mL}$ of $\mathrm{H}_{2} \mathrm{O}$ in a vial, and sonicated for $30 \mathrm{~min}$. After heating at $70{ }^{\circ} \mathrm{C}, 1 \mathrm{~g}$ of $\mathrm{TiO}_{2}$ was added, and the slurry was magnetically stirred for $12 \mathrm{~h}$. The suspension was separated by centrifugation and dried at $60{ }^{\circ} \mathrm{C}$ under vacuum and then calcinated in air at $400{ }^{\circ} \mathrm{C}$ for $2 \mathrm{~h}$ and calcinated in $10 \% \mathrm{H}_{2} / \mathrm{Ar}$ at $400{ }^{\circ} \mathrm{C}$ for $2 \mathrm{~h}$.

Preparation of Air-Pd NPs/TiO $\mathbf{2}_{\mathbf{2}}$ and Air-Pd NPs/TiO $\mathbf{2}-\mathbf{9 0 0}$. The Pd NPs/TiO and $\mathrm{Pd} \mathrm{NPs} / \mathrm{TiO}_{2}-900$ were calcinated in air at $500{ }^{\circ} \mathrm{C}$ for $3 \mathrm{~h}$ to obatin Air-Pd NPs/ $\mathrm{TiO}_{2}$ and Air-Pd NPs/TiO -900 , respectively.

Preparation of Pd NPs/TiO $\mathbf{2} @$ RF. Resorcino (10 mg), formaldehyde solution $(10 \mu \mathrm{L}, 37 \mathrm{wt} \%)$, and $\mathrm{Pd} \mathrm{NP} / \mathrm{TiO}_{2}(10 \mathrm{mg})$ were dispersed in $5 \mathrm{~mL}$ of ethanol/water solution (v/v $1: 1)$ with sodium carbonate aqueous solution $(10 \mu \mathrm{L}, 5 \mathrm{mg} / \mathrm{mL})$ as a catalyst ${ }^{44,45}$. After that, the solution was heated to $100^{\circ} \mathrm{C}$ and kept at that temperature for $24 \mathrm{~h}$. Finally, the obtained Pd NPs/TiO $\mathrm{T}_{2} @ \mathrm{RF}$ were collected and purified with distilled water by centrifugation. 
Preparation of Pd NPs/ $/ \mathrm{TiO}_{\mathbf{2}} @ \mathbf{C}$. In a typical procedure, the $\mathrm{Pd} \mathrm{NPs} / \mathrm{TiO}_{2} @ \mathrm{RF}$ power was transferred into a ceramic boat and placed in a tube furnace. The sample was annealed at $900^{\circ} \mathrm{C}$ for $3 \mathrm{~h}$ under $\mathrm{Ar}$ atmosphere with a heating rate of $5^{\circ} \mathrm{C} \mathrm{min}-1$. The obtained materials were denoted as Pd $\mathrm{NPs} / \mathrm{TiO}_{2} @ \mathrm{C}$.

Characterization. XRD measurements were recorded on a Rigaku Miniflex-600 operated at $40 \mathrm{kV}$ voltage and $15 \mathrm{~mA}$ current using a $\mathrm{Cu} \mathrm{Ka}$ radiation $(\lambda=0.15406$ $\mathrm{nm}$ ) at a step width of $2^{\circ} \mathrm{min}^{-1}$. TEM images were recorded on a Hitachi-7650 worked at $100 \mathrm{kV}$. The high-resolution TEM and the corresponding EDS were recorded on JEOL JEM-2100F field-emission electron microscope at $200 \mathrm{kV}$. HAADF-STEM images and the corresponding EDS and EELS were recorded on a FEI Titan Cubed Themis G2 300 with a probe corrector at $200 \mathrm{kV}$. The BET (Brunauer-Emmett-Teller) test was obtained from micromeritics ASAP 2020 HD88 PLUS. All the samples were degassed at $573 \mathrm{~K}$ for $3 \mathrm{~h}$. The pore size distribution was calculated from the $\mathrm{HK}$ and $\mathrm{BJH}$ method for micropores and mesopores, respectively. XPS experiments were performed at the Catalysis and Surface Science End station at the BL11U beamline of National Synchrotron Radiation Laboratory (NSRL) in Hefei, China. Thermogravimetric analyses (TGA) were carried out on a TA SDT Q600 thermal analyzer heating from room temperature to $900^{\circ} \mathrm{C}$ at the rate of $5^{\circ} \mathrm{C} \mathrm{min}-1$. Elemental analysis of $\mathrm{Pd}$ in the solid samples was detected by inductively coupled plasma atomic emission spectrometry (Optima 7300 DV). Fourier-transformed infrared resonance (FT-IR) spectra were obtained in transmission modeon a Nicolet 8700 FT-IR. Raman shifts were carried out by using a LabRAM Aramis Raman spectrometer instrument with an excitation wavelength of $514 \mathrm{~nm}$ using the Ar ion laser.

The in situ TEM study was performed on a FEI Talos F200X microscope operated at $200 \mathrm{kV}$ and an in situ gas holder (DENSsolutions Climate S3 Plus) filled with 1 bar $\operatorname{Ar}(99.9995 \%)$.

Soft X-ray absorption spectra (Soft-XAS, C K-edge, and N-K-edge) were carried out at BL12B X-ray Magnetic Circular Dichroism (XMCD) station and BL10B photoemission end station of National Synchrotron Radiation Laboratory (NSRL, Hefei in China) in TEY mode. The samples were coated on double-sided carbon tape for characterization. Hard XAFS measurement and data analysis: XAFS spectra at the Pd K-edge were recorded at the XAS station (BL14W1) of the Shanghai Synchrotron Radiation Facility (SSRF), China. The Pd K-edge XANES data were recorded in a fluorescence mode. $\mathrm{Pd}$ foil and $\mathrm{PdCl}_{2}$ were used as references. The storage ring was working at the energy of $3.5 \mathrm{GeV}$. The hard X-ray was monochromatized with $\mathrm{Si}$ (111) double-crystals. The acquired EXAFS data were extracted and processed according to the standard procedures using the ATHENA module implemented in the IFEFFIT software packages.

Catalytic evaluation. The hydrogenation reactions were operated using $25 \mathrm{~mL}$ Schlenk glass vessel tubes under $0.1 \mathrm{MPa} \mathrm{H}_{2}$ atmosphere. Specifically, different catalysts (Pd NPs/TiO 2 , Pd NPs/TiO $@$ @PDA, Pd SAs/ $/ \mathrm{TiO}_{2} @ \mathrm{C}, \mathrm{Pd} \mathrm{SAs} / \mathrm{TiO}_{2}, \mathrm{Pd}$ $\left.\mathrm{NPs} / \mathrm{TiO}_{2}-900, \mathrm{Pd} \mathrm{NPs} / \mathrm{SAs} / \mathrm{TiO}_{2}-900\right)$ and $160 \mu \mathrm{mol}$ of nitrobenzene/styrene with a mole ratio of 1:2300 (Pd: nitrobenzene/styrene) were dispersed in $5 \mathrm{~mL}$ of ethanol. For $\mathrm{TiO}_{2}-900$ and $\mathrm{Pd} \mathrm{SAs} / \mathrm{C}_{\mathrm{TiO}}, 20 \mathrm{mg}$ of catalysts and $80 \mu \mathrm{mol}$ of styrene were dispersed in $5 \mathrm{~mL}$ of ethanol. Then $\mathrm{H}_{2}$ was used to completely remove air from the reactor and stirring at $303 \mathrm{~K}$ with different time in an oil bath. For silane oxidation reactions, $0.5 \mathrm{mmol}$ of silane, Pd species catalysts (Pd SAs/ $\mathrm{TiO}_{2}, 10 \mathrm{mg}$; Pd NPs/TiO, $10.6 \mathrm{mg}$ ), $0.1 \mathrm{~mL}$ of $\mathrm{H}_{2} \mathrm{O}$ and $2 \mathrm{~mL}$ of acetone were added to a $10-\mathrm{mL}$ round bottom flask. After stirring the result mixture under room temperature for a proper time, the catalyst was removed through filtration. For alkene hydrosilylation reactions, 1-Octene $(1 \mathrm{mmol})$, triethoxysilane $(1.1 \mathrm{mmol})$, $\mathrm{Pd}$ species catalysts $\left(\mathrm{Pd} \mathrm{SAs} / \mathrm{TiO}_{2}, 15 \mathrm{mg} ; \mathrm{Pd} \mathrm{NPs} / \mathrm{TiO}_{2}, 16 \mathrm{mg}\right.$ ), and toluene (3 $\mathrm{mL}$ ) were sequentially added in a $20-\mathrm{mL}$ standard Schlenk tube, then the mixture was heated at $90^{\circ} \mathrm{C}$ and stirred for a proper time. Conversion for all reactions is determined by gas chromatography (GC) analysis with octadecane as an internal standard. Selectivities are determined by GC-MS analysis.

\section{Data availability}

The main data supporting the findings of this study are available within the article and its Supplementary Information. Extra data are available from the corresponding authors upon request.

Received: 1 August 2019; Accepted: 18 December 2019; Published online: 17 January 2020

\section{References}

1. Hansen, T. W., Delariva, A. T., Challa, S. R. \& Datye, A. K. Sintering of catalytic nanoparticles: particle migration or Ostwald Ripening? Acc. Chem. Res. 46, 1720-1730 (2013).

2. Risse, T., Shaikhutdinov, S., Nilius, N., Sterrer, M. \& Freund, H. J. Gold supported on thin oxide films: from single atoms to nanoparticles. Acc. Chem. Res. 41, 949-956 (2008).
3. Y, N., L, L. \& Z, W. Recent advancements in Pt and Pt-free catalysts for oxygen reduction reaction. Chem. Soc. Rev. 44, 2168-2201 (2015).

4. Lu, J. et al. Coking- and sintering-resistant palladium catalysts achieved through atomic layer deposition. Science 335, 1205-1208 (2015).

5. Zhan, W. et al. A sacrificial coating strategy toward enhancement of metalsupport interaction for ultrastable Au nanocatalysts. J. Am. Chem. Soc. 138, 16130-16139 (2016)

6. $\mathrm{Xu}, \mathrm{Z}$. et al. Size-dependent catalytic activity of supported metal clusters. Nature 372, 346-348 (1994).

7. Jones, J. et al. Thermally stable single-atom platinum-on-ceria catalysts via atom trapping. Science 353, 150-154 (2016).

8. Datye, A. K., Xu, Q., Kharas, K. C. \& Mccarty, J. M. Particle size distributions in heterogeneous catalysts: what do they tell us about the sintering mechanism? Catal. Today 111, 59-67 (2006).

9. Dai, Y., Lu, P., Cao, Z., Campbell, C. T. \& Xia, Y. The physical chemistry and materials science behind sinter-resistant catalysts. Chem. Soc. Rev. 47, 4314-4331 (2018)

10. Sá, J. et al. Redispersion of gold supported on oxides. ACS Catal. 2, 552-560 (2012).

11. Runhai, O., Jin-Xun, L. \& Wei-Xue, L. Atomistic theory of Ostwald ripening and disintegration of supported metal particles under reaction conditions. J. Am. Chem. Soc. 135, 1760-1771 (2013).

12. Moulijn, J. A., Diepen, A. E. V. \& Kapteijn, F. Catalyst deactivation: is it predictable?: what to do? Appl. Catal. A Gen. 212, 3-16 (2001).

13. Lin, L. et al. Low-temperature hydrogen production from water and methanol using Pt/a-MoC catalysts. Nature 544, 80-83 (2017)

14. Yao, Y. et al. High temperature shockwave stabilized single atoms. Nat. Nanotechnol. 14, 851-857 (2019).

15. Li, M. et al. Single-atom tailoring of platinum nanocatalysts for highperformance multifunctional electrocatalysis. Nat. Catal. 2, 495-503 (2019).

16. Botao, Q. et al. Single-atom catalysis of $\mathrm{CO}$ oxidation using Pt1/FeOx. Nat. Chem. 3, 634-641 (2011).

17. P, L. et al. Photochemical route for synthesizing atomically dispersed palladium catalysts. Science 352, 797-801 (2016).

18. Wei, S. et al. Direct observation of noble metal nanoparticles transforming to thermallystable single atoms. Nat. Nanotechnol. 13, 856-861 (2018).

19. Wan, J. et al. Defect effects on $\mathrm{TiO}_{2}$ nanosheets: stabilizing single atomic site $\mathrm{Au}$ and promoting catalytic properties. Adv. Mater. 30, 1705369 (2018).

20. Ming, $\mathrm{Y}$. et al. Catalytically active $\mathrm{Au}-\mathrm{O}(\mathrm{OH})_{\mathrm{x}}$-species stabilized by alkali ions on zeolites and mesoporous oxides. Science 346, 1498-1501 (2014).

21. Sang, H. J. et al. Thermally stable $\mathrm{Pt} / \mathrm{mesoporous} \mathrm{silica} \mathrm{core-shell}$ nanocatalysts for high-temperature reactions. Nat. Mater. 8, 126-131 (2009).

22. Dai, Y. et al. A sinter-resistant catalytic system based on platinum nanoparticles supported on $\mathrm{TiO} 2$ nanofibers and covered by porous silica. Angew. Chem. Int. Ed. 51, 10692-10692 (2012).

23. Seo, M., Lee, D. W., Han, S. S. \& Lee, K. Y. Direct synthesis of hydrogen peroxide from hydrogen and oxygen over mesoporous silica-shell-coated, Pdnanocrystal-grafted $\mathrm{SiO}_{2}$ nano-beads. ACS Catal. 7, 3039-3048 (2017).

24. Sun, J. M. et al. Toward monodispersed silver nanoparticles with unusual thermal stability. J. Am. Chem. Soc. 128, 15756-15764 (2006).

25. Liu, L. \& Corma, A. Metal catalysts for heterogeneous catalysis: from single atoms to nanoclusters and nanoparticles. Chem. Rev. 118, 4981-5079 (2018).

26. Chen, J., Zhang, R., Han, L., Tu, B. \& Zhao, D. One-pot synthesis of thermally stable gold@mesoporous silica core-shell nanospheres with catalytic activity. Nano Res. 6, 871-879 (2013).

27. Li, Z., Wang, D., Wu, Y. \& Li, Y. Recent advances in the precise control of isolated single-site catalysts by chemical methods. Natl Sci. Rev. 5, 673-689 (2018).

28. Peterson, E. J. et al. Low-temperature carbon monoxide oxidation catalysed by regenerable atomically dispersed palladium on alumina. Nat. Commun. $\mathbf{5}$, 4885 (2014).

29. Duan, K., Liu, Z. \& Yuan, L. Selective catalytic reduction of $\mathrm{NO}_{x}$ by hydrogen over modified $\mathrm{Pd} / \mathrm{TiO}_{2}-\mathrm{Al}_{2} \mathrm{O}_{3}$ catalyst under lean-burn conditions. Chin. Sci. Bull. 59, 3973-3979 (2014).

30. Galisteo, F. C. et al. Reactivation of sintered $\mathrm{Pt} / \mathrm{Al}_{2} \mathrm{O}_{3}$ oxidation catalysts. Appl. Catal. B 59, 227-233 (2005)

31. Wong, A., Liu, Q., Griffin, S., Nicholls, A. \& Regalbuto, J. R. Synthesis of ultrasmall, homogeneously alloyed, bimetallic nanoparticles on silica supports. Science 358, 1427-1430 (2017).

32. $\mathrm{Li}$, J. et al. Oxygen vacancy on $\mathrm{TiO}_{2}$ promoted the activity and stability of supported Pd nanoparticles for oxygen reduction reaction. J. Mater. Chem. A 6, 2264-2272 (2017).

33. Y, Z., H, Q., BA, D. \& R, J. Atomically precise Au25(SR) 18 nanoparticles as catalysts for the selective hydrogenation of alpha,beta-unsaturated ketones and aldehydes. Angew. Chem. Int. Ed. 122, 1317-1320 (2010).

34. Crooks, R. M., Zhao, M., Sun, L., Chechik, V. \& Yeung, L. K. Dendrimerencapsulated metal nanoparticles: synthesis, characterization, and applications to catalysis. Acc. Chem. Res. 32, 181-190 (2010). 
35. Lü, X. et al. Conducting Interface in oxide homojunction: understanding of superior properties in black $\mathrm{TiO}_{2}$. Nano Lett. 16, 5751-5755 (2016).

36. Lei, F. et al. Oxygen vacancies confined in ultrathin indium oxide porous sheets for promoted visible-light water splitting. J. Am. Chem. Soc. 136, 6826-6829 (2014).

37. Ou, G. et al. Tuning defects in oxides at room temperature by lithium reduction. J. Am. Chem. Soc. 136, 6826-6829 (2014)

38. Chen, X. et al. X-ray spectroscopic study of the electronic structure of visiblelight responsive $\mathrm{N}-, \mathrm{C}$ - and S-doped $\mathrm{TiO}_{2}$. J. Electron Spectrosc. 162, 67-73 (2008).

39. Lusvardi, V. S. et al. An NEXAFS investigation of the reduction and reoxidation of $\mathrm{TiO}_{2}$ (001). Surf. Sci. 397, 237-250 (1998).

40. Kronawitter, C. X. et al. Electron enrichment in $3 \mathrm{~d}$ transition metal oxide hetero-nanostructures. Nano Lett. 11, 3855-3861 (2011).

41. L, Z. et al. Platinum-based nanocages with subnanometer-thick walls and welldefined, controllable facets. Science 349, 412-416 (2015).

42. Zhang, M. et al. A metal (hydr)oxides@polymer core-shell strategy to metal single-atom materials. J. Am. Chem. Soc. 139, 10976-10979 (2017).

43. Mazumder, V. \& Sun, S. Oleylamine-mediated synthesis of Pd nanoparticles for catalytic formic acid oxidation. J. Am. Chem. Soc. 131, 4588-4589 (2009).

44. Almuhtaseb, S. A. \& Ritter, J. A. Preparation and properties of resorcinolformaldehyde organic and carbon gels. Adv. Mater. 15, 101-114 (2010).

45. Bin, D. S. et al. Controlling the compositional chemistry in single nanoparticles for functional hollow carbon nanospheres. J. Am. Chem. Soc. 139, 13492-13498 (2017)

\section{Acknowledgements}

This work was supported by National Key R\&D Program of China 2017YFA (0208300) and (0700104), the National Natural Science Foundation of China $(21522107,21671180$, 21521091, U1463202, and 21873050). We thank the photoemission endstations BL1W1B in Beijing Synchrotron Radiation Facility (BSRF), BL14W1 in Shanghai Synchrotron Radiation Facility (SSRF), BL10B and BL11U in National Synchrotron Radiation Laboratory (NSRL) for the help in characterizations and Mr Ketao Zang for assistance in using the aberration-corrected STEM.

\section{Author contributions}

Y.W. conceived the experiments and designed the study and wrote the paper. H.Z. and Y.

Z. planned synthesis, analyzed the data, and wrote the paper. J.X., W.C., J.L., and J.L.

performed the electron-microscopy characterization. H.S. and W.L. performed the DFT calculations. Z.L., X.W., Z.W. and X.H. discussed the results and commented on the paper. T.Y., X.W., Y.Y. and F.Z. drew the pictures. W.L., T.Y. and S.W. carried out the Xray structure characterization and proposed the structural model for the active sites. C.Z., W.W., M.C., B.J. and R.S. helped perform the catalytic reactions.

\section{Competing interests}

The authors declare no competing interests.

\section{Additional information}

Supplementary information is available for this paper at https://doi.org/10.1038/s41467019-14223-w.

Correspondence and requests for materials should be addressed to W.L., J.L. or Y.W.

Peer review information Nature Communications thanks Abhaya Datye and John Regalbuto for their contribution to the peer review of this work.

Reprints and permission information is available at http://www.nature.com/reprints

Publisher's note Springer Nature remains neutral with regard to jurisdictional claims in published maps and institutional affiliations.

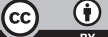
Commons license, and indicate if changes were made. The images or other third party material in this article are included in the article's Creative Commons license, unless indicated otherwise in a credit line to the material. If material is not included in the article's Creative Commons license and your intended use is not permitted by statutory regulation or exceeds the permitted use, you will need to obtain permission directly from the copyright holder. To view a copy of this license, visit http://creativecommons.org/ licenses/by/4.0/.

(C) The Author(s) 2020 